Evidence of cross-linguistic influence in the interpretation and production of generic expressions by Persian-speaking learners of English

Momenzade, Marjansadat

University of Isfahan, Iran (marymomen@yahoo.com)

Youhanaee, Manijeh

University of Isfahan, Iran (youhanaee_m@hotmail.com)

Kassaian, Zohreh

University of Isfahan, Iran (zkassaian@yahoo.com)



ISSN: 2243-7754 Online ISSN: 2243-7762

OPEN ACCESS

\title{
Abstract
}

The present study attempted to explore the acquisition of the English article system by Persian speakers. Using data elicited through a grammaticality judgment test and a translation test from forty-three learners at three levels of grammatical knowledge, it was shown that such learners had persistent difficulty in acquiring both definite and indefinite articles in English. Based on this study, it was only at the highly advanced level that learners showed mastery of the indefinite article but still remained non-native-like in their use of the definite article. Their performance also revealed sensitivity to NP function as the learners were more successful in supplying the article for object nouns. Despite the high proportion of article errors, data from Persian learners supported the predictions of the Fluctuation Hypothesis because the majority of errors were omitting the articles in obligatory contexts and not misusing the articles. Some directions are also provided for teaching the English article system to Persian speaking learners.

Keywords: article choice parameter; fluctuation hypothesis; definiteness; specificity; NP function 


\section{Evidence of cross-linguistic influence in the interpretation and production of generic expressions by Persian-speaking learners of English}

\section{Introduction}

It has repeatedly been reported by educators as well as researchers in the field that the English article system is a huge burden on the shoulders of English learners regardless of their L1 background (McEldowney, 1977; Master, 1987; Krol-Markefka, 2008; Pashazade \& Marefat, 2010 to name just a few). As a result, abundant research exists on different aspects of the article system such as acquisition and, to a lesser degree, pedagogy. This bulk of research, however, is well-devoted to the investigation of how articles, especially in English, are used to express in/definiteness or, more recently, the concept of specificity (Ionin, 2003; Hawkins et al., 2006; Avery \& Radišić, 2006; Hedberg, Görgül, \& Mamen, 2009; Atay, 2010). Few studies have so far been conducted on other aspects of article use. One such aspect is the use of articles for the expression of the concept of 'genericity'. As 'genericity' is different in nature from other features represented by the articles, that is, 'definiteness' and 'specificity', studies on the latter aspects cannot be taken to imply how the articles are used to express the former by learners.

The motivation for the present study, then, came from a desire to add to the existing literature on the generic reference in relation to the article system in English. In the following section, a review of studies on second language acquisition of generic reference in English is presented which is followed by a brief overview of the data collected from Persian learners. The fourth section presents a description of how generic reference is expressed in English and Persian. Then, information is provided on the methodology of the study. The results of the study are presented and discussed in sections 7 and 8 . The last section concludes the study and presents some pedagogical implications.

\section{Literature reviews}

\subsection{Previous studies on the acquisition of generic reference}

Snape, Garcia Mayo, and Gürel (2009) are truly right when they claim that 'little research has been conducted on the L2 acquisition of generic reference'. Most studies in the past three decades have focused on areas of article use other than the generic reference. Such studies have centered on article omission or misuse, access to semantic universals, or cognitive strategies. A few have also focused on pedagogical issues. This section, however, attends to those few studies on generic reference.

One piece of recent research to consult is that of Perez-Leroux, Munn, Schmitt, and DeIrish (2004). They investigated the acquisition of generic reference by L1 Spanish children learning English. They only considered bare plural generics in their study since in Spanish both bare plurals and definite plurals can have a generic sense but in English definite plurals cannot be interpreted as 'kind-referring'. They assumed that the definite article is semantically the same in both languages but in English the bare plural blocks the definite plural generic. They predicted that children in both languages would allow generic interpretations of the definite plural but to different degrees. In other words, the rate of acceptance of generic interpretations for the definite plural nouns would not be identical for both languages. Such interpretations would be fewer for English definite plurals. As for the results, their L1 Spanish subjects showed a 100\% preference for the generic reading of definite plurals in English, as they had predicted. The English children showed a reliable discrimination between definites and bare plurals. Nevertheless, they produced high rates of definite generic errors in their L1. The study concluded with highlighting the role of the first language in second language acquisition. 
Another study on the generic use of articles is Snape, Garcia Mayo, and Gürel's (2009). They chose learners of English from a variety of language backgrounds (Spanish, Turkish, Japanese, and Chinese) to see the effect of first language on the second language acquisition of generic noun phrases in English. The variety of L1s in their study was significant because the four languages all differed to English. In Spanish, articles are obligatory so both definite and indefinite singular/plural nouns can be interpreted as generic. This is in contrast with English in which definite plural nouns cannot be interpreted as generic. Japanese and Chinese do not have an article system. There is also no count/mass distinction in such languages. In short, bare nominals are used; singular nouns can be interpreted as generic in appropriate context; and plural nouns cannot be interpreted as generic. Turkish has no article system either but there are three ways to express genericity in Turkish: plural nouns, unmarked phrases, and bir-phrases. A forced choice elicitation task was used as the instrument. The results were as the researchers had expected. Their Spanish subjects were much more successful than the others because Spanish is a [+article] language like English but as the writers had predicted, Spanish learners at lower levels of proficiency had problems in bare plural cases due to persistent L1 transfer. Again, L1 transfer helped Turkish learners do well in indefinite singular contexts but the definite singular context was problematic for them as Turkish does not have a definite article. This again pointed to a strong L1 transfer effect. Japanese learners overused 'the' in indefinite and plural contexts since bare plurals do not exist in their L1. And finally, Chinese learners produced omission and substitution errors in all singular contexts. Like Japanese, Chinese learners substituted 'the' in bare plural contexts. What this study comes to in the end is that L1 does have a strong influence on the L2 acquisition of English articles.

The last study to be mentioned here is Ionin and Montrul's (2009). Like the study done by Perez-Leroux et al., they examined L2 acquisition of generic reference with bare plurals. Their subjects were from an article-less language (Korean) learning English as a foreign language. For an article-less language like Korean, the choice between bare and definite plural generics does not arise. A bare plural typically has a generic reference. It can also have a specific reference when used anaphorically. They hypothesized that L1 Korean learners would, like L1 Spanish learners, overuse definite plurals for generic reference, a hypothesis which was supported by the study. A truth value judgment task and an acceptability judgment task were used to elicit data from the adult Korean participants. As expected, the learners were target-like in accepting definite plurals with a specific interpretation and bare plurals with a generic interpretation, but were for the most part unable to reject bare plurals with a specific interpretation. The researchers, then, presented patterns of transfer from Korean which had caused the wrong interpretation of definite plurals.

\subsection{Previous studies on Persian-speaking learners}

The studies on Persian learners have been oriented toward determining the difficulties they face and suggesting more appropriate ways of dealing with them. Geranpaye (1995) attended to the significance of learners' errors and, based on an error analysis, argued that L1 transfer would most likely happen for Persian speakers learning the English article system where the NP carrying the article appears in subject position. He elicited data from fifteen post-graduate students at intermediate and advanced levels. Two instruments were used, a gap-filling task and an error correction task. Analysis of errors showed that the definite NP which required universal knowledge was the least problematic for all the subjects. Also, the advanced learners identified more cataphoric references than anaphoric ones. The second area with which the learners had fewer problems was specific entities. Interestingly, the researcher did not present the areas in which the subjects had most problems. $\mathrm{He}$, then, suggested, by way of conclusion, that the acquisition of English articles was delayed for most L2 learners until the very final stages of learning, a conclusion that was made based on intuition rather than evidence.

Mobini (2006) compared Iranian learners' general proficiency in English and their knowledge of articles in Persian with their performance on English articles. She claimed to have focused on the content of definite NPs in English as divided into semantic and pragmatic. Subjects in her study took two tests. On one, they were asked to fill in the blanks of an English passage with 'the' wherever necessary. On the other, they were asked to underline 
definite NPs in a Persian passage. Surprisingly, Mobini found no significant relation between learners' general English proficiency and knowledge of English articles. She also found no relation between learners' knowledge of definiteness in Persian and their accurate use of English articles. The Participants' performance on definites was more efficient in English than Persian. This, she reasoned, might have been because definiteness was an extinct grammatical concept in Persian and no definite article existed to show it. Mobini suggested that a moderate version of contrastive analysis applied to this case and that practitioners should use simple contrastive explanations in teaching the article system. Two points are worth attention in this study. First, asking learners to underline definite NPs in an L1 passage is questionable since native speakers are not expected to have explicit knowledge. It is the implicit knowledge of natives that should be tackled using an appropriate task. Second, the observation that the participants performed better on the English test than the Persian one is interesting because it shows that they had not acquired their L1!

Also, Afzali (2008) made an attempt to examine the L2 developmental sequence of article acquisition in Iranian university students and pinpointed their difficulties. She used an OPT to screen out her subjects into four proficiency groups. Later, she ran a test adapted from Ekiert (2005) that contained 75 deleted obligatory uses of articles across five semantic types of Bickerton's (1981) model as regards speaker (SR) and hearer knowledge (HK): [-SR/+HK], [+SR/+HK], [+SR/-HK], [-SR/-HK], and non-referentials. The results of the study revealed a significant difference between performance of high level learners and the rest on types 1, 4 and 5. As for type 3, only the difference between low levels and other groups was statistically significant. Finally, in case of type 2 , only the difference between low levels and other proficiency groups was considered statistically significant. Generally, the researcher suggested that types 1 and 5 were the most difficult and the last to be acquired.

Another study by Dabaghi and Tavakoli (2009) investigated the effect of error correction on EFL learners' acquisition of some grammatical features. More specifically, the study looked at the learning effects of correcting learners' errors on definite and indefinite articles as well as other grammatical features irrelevant to the focus of this study. Data for the study was collected from 56 intermediate level students of English. Through an oral interview, each participant was required to read and then retell a written text in their own words. During or following the interview, the examiners provided the participants with immediate explicit, delayed explicit and immediate implicit corrective oral feedback on their grammatical errors. Individualized multiple-choice tests focusing on the errors that had been corrected were then constructed for each participant and administered. A comparison was made between the learners' scores on the test items that measured definite and indefinite articles as well as regular and irregular past tense forms in order to assess the impact of corrective feedback on these linguistic features. The results showed that when corrective feedback was given, the definite article 'the' was learned before indefinite articles ' $a$ ' and 'an'. This finding lent support to the arguments put forth by Dietrich, Klein, and Noyau, (1995) that confirmed the role of negotiation as well as saliency and individualized attention in language learning.

The study by Pashazade and Marefat (2010) questioned the long term efficacy of written grammar feedback (WGF) on the use of articles. A group of low-intermediate EFL learners received selective grammar feedback on four writing tasks. The results supported previous research that WGF was effective in the short run. As such gains disappeared overtime, the researchers quoted Truscott (1996) in that the temporary success was not actually the result of corrective feedback but due to learners' metalinguistic knowledge and conscious control over their output.

\subsection{Genericity in English and Persian}

Lyons (1999, p. 179) gives the following definition for a generic NP:

Generic noun phrases are those in which reference is made to an entire class, or, perhaps more accurately, which are used to express generalization about a class as a whole- the class in question being that consisting of all the entities satisfying the description inherent in the noun or 
nominal.

Although genericity is a shared concept in both English and Persian, its realization is somewhat different. There is a general consensus that the concept of genericity in English can be expressed in three ways:

1. Definite article + singular NP: The dog has four legs.

2. Indefinite article + singular NP: A dog has four legs.

3. Bare plural NP: Dogs have four legs.

[Lyons, 1999, p. 179]

In their article, Smólska and Rusiecki (1980) discuss differing views on the three types of genericity in English. Whereas a few researchers believe that the above mentioned three forms are the same and, in fact, interchangeable (Robbins, 1970), there are some who believe the forms are not interchangeable and denote different meanings (Langendoen, 1970; Quirk, Greenbaum, \& Svartvik, 1972). Also, predicate type has an effect on which form of the generic NP would be acceptable in a given context. There is a difference between generics which predicate something of each member of the class and generics which predicate something of the class as an entity. The following examples are adopted from Lyons (1999, p. 182):

4.

The dodo is extinct.

Dodos are extinct.

*A dodo is extinct.

5.

The lion hunts the antelope.

The lion hunts antelopes.

*The lion hunts an antelope.

It is clear from the examples above that the position of the NP within the sentence as subject or object does not determine the form of the generic expression which is acceptable. Rather, it is the predicate which is the determining factor. This seems to support those who believe that the forms are not interchangeable. This line of discussion is not, however, more elaborately presented here as it is not of interest to this study (for more details see Lyons 1999). The present study is based on the concept of generic noun phrases simply as "kind-referring expressions" that do not refer to a specific referent.

In Persian, on the other hand, the concept of genericity is stated in two ways:

6. Bare singular NP: shotor beh-tærin $\quad$ væsileh bæraye sæfær dær biyaban æst.

Camel best-superlative means for travel in desert is.

"The camel is the best means for travelling in the desert."

7. Bare plural NP: gol-ha be nur ehtiyaj dar-ænd.

Flower-Plu to light needs have-3rd Plu

"Flowers need light." 
Momenzade, M., Youhanaee, M., \& Kassaian, Z.

Two points are worth attention with regard to the generic NPs in Persian. First, bare plural NPs are ambiguous in their interpretation as generic or definite. A bare plural NP can also be interpreted as definite based on the context. As mentioned, the example 7 above can be interpreted as generic. But it is quite common for the speaker to refer to the flowers in his/her garden for instance, in which case the resulting NP would be definite and the equivalent English translation would be "The flowers need light". It is the context, then, which determines the appropriate interpretation of the NP.

Second, bare plural NPs cannot be used interchangeably with bare singular NPs in all contexts. As an example:

8. diruz bæra-sh gol xarid-æm.

Yesterday for-her flower buy-1st Sing

"I bought flowers for her yesterday."

The generic bare singular NP in this sentence (gol) cannot be substituted with its bare plural form:

9. *diruz bæra-sh gol-ha xarid-æm.

*yesterday for-her flower-Plu buy-1st Sing

*"I bought flowers for her yesterday."

Although the English equivalent would be correct, this not the way it is in Persian. In other words, there are restrictions on the use of bare singular/plural generic nouns in Persian determined by the context.

Clearly, there are differences between the two languages. For one thing, the first type of generic NP in English that is listed above (the $+\mathrm{N}$ ) is not found in Persian due to the fact that there is no equivalent to the English definite article, at least in the formal language and writing. For another, an NP that is marked by the indefinite article (which is overtly realized in Persian) cannot be normally interpreted as generic. In other words, the second type of English generic construction $(\mathrm{a}+\mathrm{N})$ is not found in Persian either. The only point of similarity that can be observed between the two languages is the third type of generic construction. Bare plurals can be used in a generic sense in both Persian and English. So, in Persian, only bare singular nouns and bare plural nouns can be interpreted as generic.

\section{Method}

\subsection{Research questions}

Considering the EFL context in which Persian learners study English and the similarities and differences in the expression of generic reference across the two languages, the present study sought answers to the following questions:

$>$ At which level of grammatical knowledge do Persian-speaking learners gain native-like mastery in article use for generic reference?

$>\quad$ Which article do they prefer for the expression of generic reference?

\subsection{Participants}

Fifty English students at the University of Sheikhbahaee were screened out into three groups of grammatical knowledge based on their performance on the Oxford Placement Test (2001). The highly advanced group included those participants who could score 55-60 on the OPT. They were ten in number. The intermediate group 
consisted of seventeen participants who could score 40-45 on the OPT. The elementary group included twenty-three participants who scored 25-30 on the placement test. The researchers preferred to include bigger gaps among the groups than were considered in the original OPT manual in order to make sure that the groups truly belonged to different levels of L2 grammatical knowledge. Fifteen native speakers were also included in the study as the control group. They all were originally Americans having lived in their home county all their lives, having had almost no contacts with non-native speakers.

\subsection{Instruments}

The measurements in the present study were a grammaticality judgment task (GJ) and a translation task. Each item on the GJ task included two sentences the first of which provided the necessary context for the interpretation of the second one. The noun phrase in question was placed in the second sentence. The participants were asked to determine if the second sentence was correct or not in the context of the first. They were also asked to correct the second sentence in case they thought it were wrong. An example item is given below:

Whenever I lose something, my dog finds it for me. Dogs are very intelligent. $\quad \sqrt{ } * \quad * \quad$ ?

The task included 50 items 28 of which were of interest to this study. The rest of the items (twenty-two in number) tested other aspects of grammar (tense for example) and were included to distract learners' attention from the point being tested. The items which included generic expressions were equally distributed for grammaticality and number. More simply, of the twenty-eight items, half were grammatical and included seven singular and seven plural generic NPs. The ungrammatical items (also 14 in number) included seven singular and 7 plural items to be corrected.

The translation task included 16 generic sentences and 14 distracters. Some of the categories on this task were similar to the ones on the GJ task but there were also categories which were not found in the former. The reason was that this task was constructed based on the concept of genericity in Persian. The purpose of developing the translation task was to detect possible L1 transfer effects on how Persian-speaking EFL learners used the article system in English.

\section{Results}

As for performance on the GJ task (Figure 1), the participants were more successful in handling the plural generic NPs and had more problems in recognizing and, in case of the ungrammatical items, correcting the singular generic nouns.

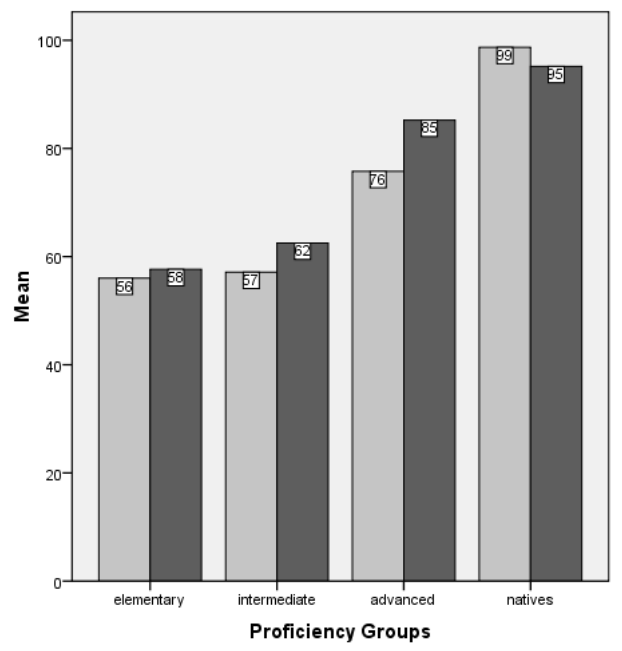

Figure 1. Mean accuracy scores (\%) for generic nouns on the GJ task 
Momenzade, M., Youhanaee, M., \& Kassaian, Z.

To see if the difference in performance among the four groups was meaningful, a one-way between groups analysis of variance (ANOVA) was conducted the result of which pointed to a significant difference in performance among the four groups of participants (Table 1). Based on a post-hoc Scheffe test, considering singular generic NPs, it was shown that none of the learner groups conformed to the native speaker norm as there was a significant difference detected. For the plural generic items, however, the advanced group performed similarly to the native speakers.

Table 1

ANOVA Results for Generic Nouns on the GJ Task

\begin{tabular}{lllllll}
\hline & & Sum of Squares & df & Mean Square & F & Sig. \\
\hline Singular & Between Groups & 16918.526 & 3 & 5639.509 & 27.434 & .000 \\
& Within Groups & 10689.361 & 52 & 205.565 & & \\
& Total & 27607.887 & 55 & & & .000 \\
& Between Groups & 13837.892 & 3 & 4612.631 & 24.370 & \\
& Within Groups & 9842.354 & 52 & 189.276 & & \\
& Total & 23680.246 & 55 & & & \\
\hline
\end{tabular}

Moreover, paired-samples t-tests were conducted to see if the difference in performance on plural vs. singular items within each group was significant. The result was negative for all three learner groups.

Since the GJ task included both grammatical and ungrammatical items, it would be more revealing if we consider performance on each item type in the task in that specific areas of difficulty would show up. This is provided in Figure 2 below. Obviously, low performance on the generic items at the three levels can be traced back to the participants' inability to recognize cases of incorrect article use within the sentences and to make corrections as they were much more able to recognize grammatical sentences on the task. In other words, their performance on grammatical and ungrammatical sentences was not at all comparable. This is true for both singular and plural generic NPs.

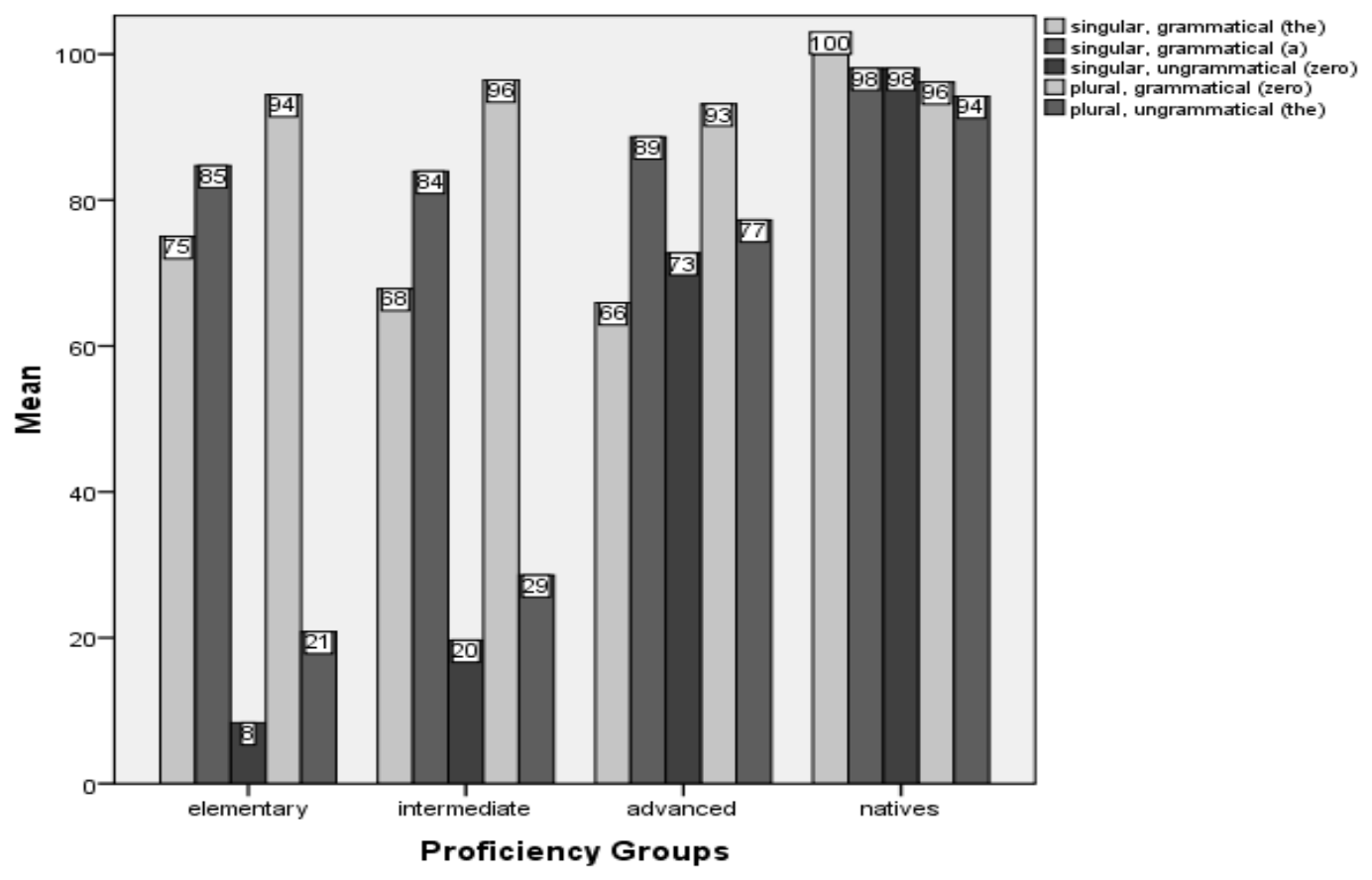

Figure 2. Mean accuracy scores (\%) for generic subcategories on the GJ task 
On the other hand, performance on grammatical plural generics was better than that on grammatical singular generics. The learners could well recognize correct sentences that included a bare plural (for example: Dogs are pets.) even at the elementary level, but when they were expected to correct the generic plural nouns ungrammatically appearing with 'the' (for example: The dogs are pets.), they severely failed to do so at the elementary and intermediate levels. At the advanced level, they were still non-native-like as it is evidently shown on the figure.

The results obtained from the translation task were similar to the ones from the GJ task. From among the sub-categories of generic nouns on the translation task, the learners had a better performance on plural nouns which was more noticeable at the elementary and intermediate levels. (Figure 3)

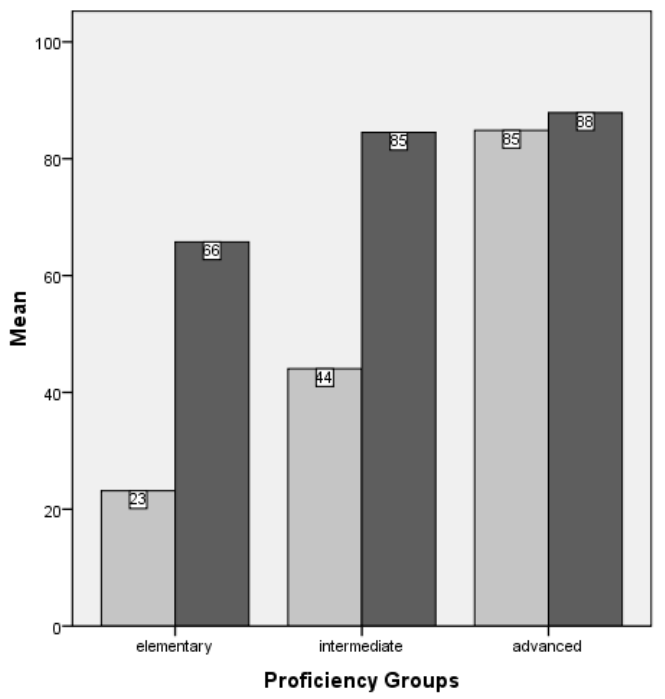

口singular
plural

Figure 3. Mean accuracy scores (\%) for generic nouns on the translation task

The one-way between groups analysis of variance (Table 2) showed that the three learner groups were different in performance from each other.

Table 2

ANOVA Results for Generic Nouns on the Translation Task

\begin{tabular}{llllllc}
\hline & & Sum of Squares & df & Mean Square & F & Sig. \\
\hline Singular & Between Groups & 26051.359 & 2 & 13025.679 & 42.244 & .000 \\
& Within Groups & 12333.654 & 40 & 308.341 & & \\
& Total & 38385.013 & 42 & & & \\
\hline Plural & Between Groups & 4364.613 & 2 & 2182.307 & 4.906 & .012 \\
& Within Groups & 17793.009 & 40 & 444.825 & & \\
& Total & 22157.623 & 42 & & & \\
\hline
\end{tabular}

The post-hoc Scheffe test indicated that, in article use for singular generics, the elementary group was significantly different from the other two groups. The intermediate group was also significantly different from the advanced group in supplying the correct article. For plural generics, however, only the elementary group could not do as well as the advanced group and the difference reached statistical significance. Paired-samples t-tests also showed that within group differences observed in the above (Figure 3) were also significant for the elementary group and the intermediate group.

\section{Discussion}

As discussed previously (section 4 above), generic forms in English and Persian do not correspond. Generic singular and plural nouns take different articles in English but they appear in bare forms in Persian. That's why 
the participants had better performance on plural generic nouns in English. One interpretation would be that plural generics were easier for them to handle since they have the same form in both L1 and L2, hence the effect of positive L1 transfer. Such conclusion is, however, doubtful. Bearing in mind that such learners failed to correct sentences which included a generic NP incorrectly appearing with 'the' on the GJ task (for example: The dogs are pets.), the seemingly better performance can also be interpreted as a case of indetermination. In other words, such learners had not learnt to use plural English nouns in a generic sense. They were only showing their lack of knowledge of how English articles work. The evidence for such a claim would be their tendency to omit the article with singular generic nouns. These learners were simply omitting the article for both singular and plural nouns in their generic sense. Another piece of evidence is that they could well recognize grammatical sentences on the GJ task as correct (Figure 1) but their significant ignorance about the ungrammatical form, in fact, shows that they were not accurate in using the correct form but were also ignorant of the bare plural forms that carry a generic meaning. They just tended to omit the article in all contexts. The answer to the first research question would, then, be negative. Even the advanced participants did not show to have achieved native-like mastery over the English article system for the expression of generic reference.

Considering singular generic NPs, the Persian-speaking learners displayed serious difficulties in supplying the appropriate article. Even the advanced participants, who had a more acceptable performance than the other two groups, did supply an article just for $20 \%$ of the singular contexts on the translation task and preferred the plural form with a 'zero' article for the rest (80\%). Evidence was also provided by performance on the GJ task (Figure 1) that even the grammatical singular generic NPs had been recognized as ungrammatical by the participants and in those few cases where grammatical sentences had been confirmed as so, preference had been given to ' $a$ ' to occur with singular generics than 'the'. The participants in all three learner groups showed that singular generic NPs which appeared with 'the' were the least accepted form for them. Still more, analysis of the participants' corrections on the GJ task showed that in cases where the participants had been able to correct ungrammatical sentences, they had used 'zero' article plus the plural NP (that is, a bare plural generic NP) much more frequently than the singular form used with ' $a$ ' or 'the'. It seems that such learners consider 'the' as a marker of definiteness and ' $a$ ' as a marker of indefiniteness and using these articles with generic NPs is considered out of the question. Interestingly, on both the translation task and the GJ task, the participants' performance on the singular generics did not differ significantly. This pointed to a case of fossilized knowledge. English singular generics were unacceptable for all Persian-speaking learners in this study regardless of their grammatical proficiency. The fossilization was more noticeable in case of singular generics with 'the' as the advanced participants were even less successful than the elementary learners on such items. What differentiated the three groups, in fact, was the extent to which they were able to recognize the generic sense of the sentence and to use a bare plural NP. As an answer to the second research question, then, singular generics with ' $a$ ' were preferred over those with 'the'. It doesn't, however, mean that such learners were comfortable with using the indefinite article with generic expressions. Rather, a tendency was found toward accepting one article over the other when they were to recognize the sentences that included a singular generic NP on the task. Analysis of the learners' translations at all three levels showed that, when they produced a singular generic noun, 'the' and 'a' had been used with the same proportion (10\% each in the total $20 \%$ production of singular generics). The participants' expression of generic reference points to strong L1 effects, though. At all three levels of grammatical knowledge they favored 'the $+\mathrm{N}$ ' generics the least which can be explained by the fact that such a form does not exist in Persian. They also barely accepted indefinite singular generics as grammatical which, again, is an L1 effect. Though the indefinite article exists in Persian, it is not used to form a generic expression.

\section{Conclusion}

The effect of first language transfer was observed in the performance of Persian-speaking learners in the present study in that they produced bare forms of generic NPs either singular or plural. In case of plural generics, their productions were correct but it was argued that they were not an indicator of knowledge of generics simply because the participants tended to omit the article in both singular and plural generic expressions. Still more, 
they were unable to recognize definite plural expressions as non-generic. Even at the highly advanced level of grammatical knowledge, our participants displayed gaps in their knowledge of generics which made them different from the native speakers in performance. In very few cases which they did show some knowledge of the form of singular generic nouns in English, they preferred the ' $\mathrm{a}+\mathrm{N}$ ' form over the 'the+N' form. In other cases, the plural form was preferred over the singular one.

The way the participants performed is seriously affected by L1 transfer which is impeding the learners from correct use of generic expressions. As to the reasons, how English articles are taught in the EFL context of Persia may be considered the primary source. As mentioned above, Persian-speakers associate the English articles with 'in/definiteness' and fail to use them with generic NPs simply because they have been taught so. The focus of instruction is on using articles to imply whether a noun is definite or indefinite discarding how they are used to imply genericity. This area of article use clearly needs more attention on the part of instructors, then. It is obvious that learners need instruction and practice regarding both meaning and form. Pedagogical work can range from simple contrastive bilingual lists to more complex activities such as focus-on-form tasks. One such tasks are consciousness-raising tasks which, in Nunan's terms (2004, p. 98), are designed 'to draw learners' attention to a particular linguistic feature'. These tasks seem to be especially helpful because they cater to explicit learning. As with the participants in the present study, one can conclude that implicit learning must have had little effect and that, generally speaking, learners need to be explicitly taught the similarities and differences in form and meaning. However, these are speculations about the pedagogical aspect of the issue and need to be employed empirically before one can strongly recommend any particular methodology. At least to our knowledge, no study has been reported so far on the teaching of English articles as they relate to the realm of generic expressions to Persian speakers. Highlighting the specific cases of difficulty, the present study could be taken as a launching pad for further research.

\section{References}

Afzali, K. (2008). An interlanguage study of article acquisition by Iranian students: A semantic perspective. Sheikhbahaee Research Bulletin, 5, 71- 88.

Atay, Z. (2010). Second language acquisition of the English article system by Turkish learners: The role of semantic notions. Unpublished masteral thesis, Middle East Technical University, Ankara, Turkey.

Avery, P., \& Radišić, M. (2006). Accounting for variability in the acquisition of English articles. In Proceedings of the 2nd Conference on Generative Approaches to Language Acquisition North America (GALANA) (pp. 1-11). Somerville, MA: Cascadilla Proceedings Project.

Bickerton, D. (1981). Roots of language. Ann Arbor, MI: Karoma.

Carlson, G. N. (1980). Reference to kinds in English. Garland Publishing Inc: New York \& London.

Carlson, G. N., \& Pelletier, F. J. (2002). The average American has 2.3 children. Journal of semantics, 19, 1-32. http://dx.doi.org/10.1093/jos/19.1.73

Dabaghi, A., \& Tavakoli, M. (2009). A comparison of the effects of corrections on definite/indefinite articles and regular/irregular past tense forms: A case of Iranian EFL learners. Asian EFL Journal, 11(4), 90-114.

Dietrich, R., Klein, W., \& Noyau, C. (1995). The acquisition of temporality in a second language. Amsterdam: John Benjamins.

Ekiert, M. (2005). Acquisition of the English article system by speakers of Polish in ESL and EFL settings. TESOL \& Applied Linguistics, 4(1), 1-23.

Geranpaye, A. (1995). The English article system and Farsi speakers. International Journal of humanities, 6(2), 44-55.

Hawkins, R. et al. (2006). Accounting for English article interpretation by L2 speakers. In S. Foster-Cohen, M. Medved Krajnovic, \& J. Miihaljevic Djigunovic (Eds.), EUROSLA Yearbook. Amsterdam: John Benjamins.

Hedberg. N., Görgül. E., \& Mamen. M. (2009). On definiteness and specificity in Turkish and Persian. In Proceedings of the 2009 Annual Conference of the Canadian Linguistic Association (pp. 1-15), Carleton 
Momenzade, M., Youhanaee, M., \& Kassaian, Z.

University, Ottawa, Ontario.

Ionin, T. (2003). Article semantics in second language acquisition. Unpublished doctoral dissertation, MIT.

Ionin, T., \& Montrul, S. (2009). Article use and generic reference: Parallels between L1 and L2 acquisition. In M. Garcia-Mayo, \& R. Hawkins (Eds.), Second language acquisition of articles: Empirical findings and theoretical implications. Amsterdam: John Benjamins.

Juvan, M. (2005). Generic identity and intertextuality. CLC Web: Comparative literature and culture, 7(1), 1-11.

Król-Markefka, A. (2008). Some theoretical considerations on the use of contrastive data in teaching English articles to Polish learners. Studia Linguistica, 125, 103-112.

Langendoen, D. T. (1970). Essentials of English grammar. New York: Holt, Rinehart and Winston.

Lyons, C. (1999). Definiteness. Cambridge: Cambridge University Press. http://dx.doi.org/10.1017/CBO9780511605789

Master, P. (1987). A cross-linguistic interlanguage analysis of the acquisition of the English article system. Unpublished doctoral dissertation, UCLA.

McEldowney, P. (1977). A teaching grammar of the English article system. International Review of Applied Linguistics, 15(1), 95-112.

Mobini, F. (2006). Farsi speaking learners' differential commands of semantic vs. pragmatic definite types: A cross linguistic study. Unpublished doctoral dissertation, University of Isfahan, Iran.

Nunan, D. (2004). Task-based language teaching. Cambridge: Cambridge University Press. http://dx.doi.org/10.1017/CBO9780511667336

Pashazadeh, A., \& Marefat, H. (2010). The long term effect of selective written grammar feedback on EFL learners' acquisition of articles. Pazhuhesh-e Zabanha-ye Khareji, 56, $49-67$.

Pérez-Leroux, A., Munn, A., Schmitt, C., \& DeIrish, M. (2004). Learning definite determiners: Genericity and definiteness in English and Spanish. In A. Brugos, L. Micciulla, \& C. Smith (Eds.), BUCLD 28 Proceedings Supplement.

Quirk, R. S., Greenbaum, G., \& Svartvik, J. (1972). A grammar of contemporary English. London: Longman.

Robbins, B. F. (1970). The definite article in English transformations. The Hague: Mouton.

Smólska, J., \& Rusiecki, J. (1980). The generic noun phrase in English and Polish. Papers and studies in contrastive linguistics, 11, 39-57.

Snape, N., Garcia Mayo, M. P., \& Gürel, A. (2009). Spanish, Turkish, Japanese and Chinese L2 learners' acquisition of generic reference. In Proceedings of the 10th Generative Approaches to Second Language Acquisition Conference (GASLA) (pp. 1-8). Somerville, MA: Cascadilla Proceedings Project.

Truscott, J. (1996). The case against grammar correction in L2 writing classes. Language Learning, 46, 327-369. http://dx.doi.org/10.1111/j.1467-1770.1996.tb01238.x 